\title{
DOSSIÊ
}

\section{Representações do Continente Africano nas Telas do Cinema Hollywoodiano ${ }^{1}$}

\author{
Representations of the African Continent on \\ Hollywood Cinema Screens
}

\author{
Renata Barbosa Melo do Nascimeno \\ Doutoranda em História na Universidade de Brasília \\ orcid.org/0000-0003-3858-8682 \\ rmbnascim@gmail.com
}

\begin{abstract}
RESUMO: Este artigo tem como tema a análise das representações do continente africano no Cinema, através dos filmes Hotel Ruanda (2004) e O último Rei da Escócia (2006). Propõese uma análise a partir dos estudos decoloniais de modo a observar os pressupostos em que se ancoram estas representações, enfatizando as suas condições de produção. Trata-se, portanto, de apreender confluências quanto às imagens e lugares atribuídos às populações do continente africano, desvendando conexões históricas e culturais. Por outro lado, busca-se apreender também a variabilidade e as divergências na maneira como o continente é retratado nos filmes em questão, com atenção às ênfases de cada cineasta.
\end{abstract}

PALAVRAS-CHAVE: Representações. Continente Africano. Cinema.

\begin{abstract}
This article examines the representations of the African continent in Cinema through the films Hotel Rwanda (2004) and The Last King of Scotland (2006). An analysis is proposed from the decolonial studies in order to observe the presuppositions in which these representations are anchored, emphasizing their conditions of production. It is therefore a question of understanding confluences as to the images and places attributed to the populations of the African continent, unraveling historical and cultural connections. On the other hand, the aim is also to understand the variability and divergences in the way of continent is portrayed in the films in question, paying attention to the emphases of each filmmaker.
\end{abstract}

KEYWORDS: Representations. African continente. Cinema.

\section{O Cinema como fonte histórica}

A importância do cinema como fonte histórica vem sendo assumida por vários historiadores/as desde os anos de 1960 e 1970 (MISKELL, 2011, p. 283). Elevado à categoria de "novo objeto", foi incorporado ao fazer historiográfico a partir das mudanças

\footnotetext{
${ }^{1}$ Este artigo é uma adaptação do trabalho final apresentado originalmente para a obtenção do título de Especialista em História e Cultura Afro-Brasileira e Africana na Universidade Federal de Goiás - UFG em 2018.
} 
Revista do Corpo Discente do Programa de Pós-Graduação em História da UnB

Em TEMPO DE HIsTóRIAS | Brasília-DF | n. 37 | p. 28-44 | jul./dez. 2020.

ISSN 2316-1191

introduzidas pela Nova História ${ }^{2}$ (MORETTIN, 2003, p.12), e neste caso, destacamos o historiador Marc Ferro por ser um dos pioneiros ao discutir o cinema como documento histórico (NASCIMENTO, 2014, p. 6). Percebemos nitidamente o quanto os cineastas são produtores culturais, nos levando perceber a importância de suas produções historiográficas e suas respectivas representações, apesar de que ainda nos dias atuais exista um número razoável de historiadores/as que desconfiam da relevância e as inúmeras possibilidades de análise para o fazer historiográfico.

Fica evidente que ao longo do século XX, o cinema foi ganhando espaço e conquistando um grande público, pois as imagens, sons e diálogos que difunde são capazes de incidir em nossos imaginários e na construção de percep̧̧ões de mundo, norteando nossas práticas sociais. Nessa linha de raciocínio a historiadora Mônica Kornis afirma que:

[...] o filme adquiriu de fato o estatuto de fonte preciosa para a compreensão dos comportamentos, das visões de mundo, dos valores, das identidades e das ideologias de uma sociedade ou de um momento histórico. Os vários tipos de registro fílmico - ficção, documentário, cinejornal e atualidades - vistos como meio de representação da história, refletem contudo de forma particular sobre esses temas. Isto significa que o filme pode tornar-se um documento para a pesquisa histórica, na medida em que articula ao contexto histórico e social que o produziu um conjunto de elementos intrínsecos à própria expressão cinematográfica [...] (1992, p. 239).

No que se refere às representações do continente africano, fica evidente que a historiografia do século XIX, de um modo geral, produziu e disseminou uma série de representações que povoam o nosso imaginário social, no sentido do excêntrico, do exótico, do rudimentar. Em muitos dos escritos que ganharam então destaque, predominaram imagens de homens e mulheres animalizados, subservientes, promíscuos e ignorantes, ou seja, destituídos de humanidade ou infantilizados, sem contar os inúmeros livros didáticos que corroboram para a construção destes imaginários. ${ }^{3}$

Para que possamos adentrar no conceito de representação, nos pautamos na perspectiva de Stuart Hall, onde tais representações são pensadas enquanto formas de produção de sentido, para que "uma parte essencial do processo pelo qual os significados são produzidos e compartilhados entre os membros de uma cultura", está diretamente ligado as suas relações com as identidades, os conhecimentos e o poder. Trata-se de uma prática simbólica constitutiva do real, pois tais representações envolvem "o uso da linguagem, de signos e imagens que significam ou representam objetos", condicionando a construção de processos capazes de regular condutas, inventar ou construir identidades e subjetividades forjadas do real. (2016, p.32).

A constante reiteração, repetição de representações que reforçam a inferioridade, submissão, opressão, exploração sexual e do trabalho dos/as negros/as, seja na literatura, no cinema (histórico ou de ficção), ou na própria historiografia, acabou legitimando e reforçando a discriminação e o preconceito racial e sexual em nossa sociedade (NASCIMENTO, 2014, p.12), as representações reiteradas e veiculadas, em relação ao continente africano, contribuíram para a fixação dessas representações

2 Ver LE GOFF (1978, 1984), NORA (1976) e GARÇON (1992).

${ }^{3}$ Ver OLIVA (2009). 
Revista do Corpo Discente do Programa de Pós-Graduação em História da UnB

Em TEMPO dE HISTÓRIAS | Brasília-DF | n. 37 | p. 28-44 | jul./dez. 2020.

ISSN 2316-1191

negativas, tendenciosas à um olhar colonizado, muito a contento na lógica de uma perspectiva eurocêntrica.

Neste caso, é importante mencionar que temos atualmente diversos estudos que abordam o "cinema africano", e que neste trabalho não é nosso objeto central, porém vale como ilustração para conhecer uma vertente cinematográfica que tem cineastas, produtores, roteiristas de diversos países africanos como o Egito, Burquina Fasso, Gana, Nigéria, Angola, Moçambique, África do Sul; que em suas trajetórias construíram perspectivas próprias cinematográficas, tendo como pano de fundo, as marcas deixadas pelas experiências do colonialismo e do neocolonialismo europeu. ${ }^{4}$

No que diz respeito especificamente aos filmes a serem analisados e seus respectivos diretores, iremos mergulhar nas condições de produção. Trata-se de produções hollywoodianas ${ }^{5}$ com grande repercussão, cuja crítica se volta para momentos históricos do continente africano retratados nas respectivas películas. Os filmes, suas recepções pelas críticas, configuram ferramentas positivas para trabalhar o continente como documento histórico. Portanto, cabe aqui uma breve sinopse dessas obras:

Hotel Ruanda de 2004, direção de Jerry George, tem como principal característica, o conflito político que ocorreu em 1994 em Ruanda, levando a morte de quase um milhão de pessoas em apenas cem dias. Sem apoio dos demais países, os ruandeses tiveram que buscar saídas em seu próprio cotidiano para sobreviver. Uma delas foi oferecida por Paul Rusesabagina, homem negro, ruandense, que era gerente do Hotel Milles Collines, localizado na capital do país. Contando apenas com sua coragem e inteligência, Paul abrigou no hotel mais de 1.200 pessoas durante o conflito.

O último Rei da Escócia de 2006, direção de Kevin Macdonald, conta a trajetória de Nicholas Garrigan, um médico escocês, branco, jovem, que deixou recentemente a faculdade de medicina. Ele parte para Uganda em busca de aventura, romance e divertimento, com o objetivo de ajudar um país que precisava muito de suas habilidades médicas. Logo após sua chegada, Nicholas é levado ao local de um acidente inusitado, onde o líder negro, recém empossado do país Idi Amin (Forest Whitaker), atropelou uma vaca com seu Maserati. Nicholas consegue dominar a situação, o que impressiona Amin, pessoa obcecada pela cultura e a história da Escócia, Amin se afeiçoa a Nicholas e lhe oferece a oportunidade de ser seu médico particular. Ele acaba aceitando a oferta, fazendo com que passasse a frequentar o círculo interno de um dos mais terríveis ditadores de um país africano.

As narrativas desses filmes retratam diversas vertentes de dois distintos países que compõem o continente africano - Ruanda e Uganda, respeitando suas especificidades culturais e sociais; porém a pergunta que se faz é como esses mesmos filmes contribuem por meio de suas narrativas/representações, para a construção de certos imaginários (ou cultura histórica) relativas ao continente, que se apresentam em diversos discursos como algo homogêneo, sem especificidades ou subjetividades

\footnotetext{
4 Ver: FERREIRA (2014) e BAMBA, MELEIRO (2012).

5 Classificação adaptada para identificar filmes de grande impacto de público, crítica e mídias. Ainda que não especificamente de produção norte-amaricana, mas que contam com atores, diretores e produção de profissionais com trânsito nos filmes correntes na indústria de Hollywood e que foram indicados ou ganharam o prêmio máximo da academia de cinema norte-americana o Oscar (SENGER, 2012, p.546).
} 
Revista do Corpo Discente do Programa de Pós-Graduação em História da UnB

Em TEMPO dE HISTÓRIAS | Brasília-DF | n. 37 | p. 28-44 | jul./dez. 2020.

ISSN 2316-1191

próprias, comuns a uma epistemologia ocidental/eurocêntrica. Como esses diretores conseguiram trabalhar estas representações, levando em conta o contexto contemporâneo do continente africano?

O intuito desse artigo é também tentar delinear um fio condutor dessas narrativas, destacando como essas obras contribuiriam para trabalhar o continente africano dentro de suas próprias perspectivas. Isso implica problematizar possíveis estereótipos reproduzidos nos filmes, decorrentes dentre outros aspectos, dos parâmetros hollywoodianos, especificamente por meio do cotejamento com outras fontes, como por exemplo, as produções feitas por cineastas africanos, que desvelem visões próprias do continente, numa perspectiva decolonial ${ }^{6}$ que respeita um lugar de fala não eurocentrado, portanto, uma perspectiva epistemológica própria de contar sua própria história. ${ }^{7}$

\section{As Representações Eurocêntricas nas Produções Hollywoodianas}

As produções hollywoodianas normalmente são carregadas de narrativas que referendam perspectivas eurocêntricas, imbuídas de representações do continente africano calcadas em concep̧̧ões hierarquizadas, fundamentadas em teorias de hierarquia racial semelhantes ao que foi amplamente difundido no século XIX pela historiografia.

Nessa perspectiva, a reprodução vem sendo traduzida por estereótipos bem demarcados, apresentando padrões opressivos carregados de preconceitos, com retratos negativos e depreciativos de uma sociedade historicamente fragilizada perante o olhar ocidentalizado e recorrente em tais artefatos culturais. Ella Shohat e Robert Stam enfatizam que:

[...] Para Gobineau, os negros estão no degrau mais baixo, incapazes de desenvolvimento, enquanto a raça "amarela" é superior à negra, mas ainda assim passível e suscetível de controle pelo despotismo. A raça branca, caracterizada pela inteligência, ordem e gosto pela liberdade, ocupa a posição no topo. Também para Renan os negros (assim como os povos indígenas) estão no nível mais baixo, os asiáticos são uma raça "intermediária" e os brancos europeus estão posicionados no nível mais alto (2006, p. 292).

Vemos que deliberadamente as tramas são carregadas de personagens negros/as imbuídos de uma subserviência nata, apresentando invariavelmente uma moralidade duvidosa, ou uma infantilização extremamente incômoda, ou "um cinema de imagens

\footnotetext{
${ }^{6} \mathrm{O}$ termo decolonial deriva de uma perspectiva teórica formulada no final dos anos 1990 por intelectuais latino-americanos, situados em diversas universidades das Américas; trazendo referência às possibilidades de um pensamento crítico a partir dos subalternizados pela modernidade capitalista e, numa construção de um projeto teórico voltado para o pensamento crítico e transdisciplinar, caracterizando como força política para se contrapor às tendências acadêmicas dominantes de perspectiva eurocêntrica de construção do conhecimento histórico e social; que nos aponta a necessidade de construção de um novo olhar para pensar outros contextos e sociedades. (OLIVEIRA, CANDAU, 2010).

7 Vale ilustrar os principais intelectuais decoloniais: o filósofo argentino Enrique Dussel, o sociólogo peruano Aníbal Quijano, o semiólogo e teórico cultural argentino-norteamericano Walter Mignolo, o sociólogo porto-riquenho Ramón Grosfoguel, a linguista norte-americana radicada no Equador Catherine Walsh, o antropólogo colombiano Arturo Escobar, entre outros (OLIVEIRA, CANDAU, 2010).
} 
Revista do Corpo Discente do Programa de Pós-Graduação em História da UnB

Em TEMPO dE HISTÓRIAS | Brasília-DF | n. 37 | p. 28-44 | jul./dez. 2020.

ISSN 2316-1191

artificialmente positivas deixando transparecer uma falta de confiança no grupo retratado, que por sua vez raramente tem ilusões sobre sua própria perfeição" (SHOHAT e STAM, 2006, p. 296), portanto, bem distante de uma realidade minimamente coerente.

Notadamente temos a percepção de que as representações são carregadas de imagens de guerras, conflitos étnicos, pobreza extrema, paisagens marcadas por florestas, desertos, animais selvagens; não dando ênfase a imensa diversidade que o continente possui, muito distante da homogeneidade naturalizada nas telas do cinema, e/ou na historiografia eurocêntrica. De maneira mais atenta, podemos perceber que há uma parte considerável de deserto no continente africano, com a existência de rios muito extensos e volumosos, localizados em regiões tropicais e equatoriais, atravessando áreas desérticas, dando assim condições de sobrevivência para as populações locais, distanciando - se dos estereótipos que normalmente nos é apresentado.

Se a invisibilização da diversidade do continente africano se verifica na historiografia "em geral", o mesmo se reproduz no cinema hollywoodiano, tanto é assim que:

Associado, por várias vezes, a não civilização, os filmes "se esquecem" de retratar a diversidade e pluralidade existente no continente africano, destacando somente os problemas da fome, guerras e doenças. Tais situações existem em algumas regiões, mas não podem ser indicadas como uma constante generalizada [...], (LOPES, 2017, p. 51)

Na perspectiva das produções hollywoodianas há variadas imposições culturais, apagamentos de memórias dos países retratados e sujeições identitárias advindas de um olhar colonizado, que nada mais é que uma usurpação flagrante de uma memória desvalorizada; carregada de representações naturalizadas como "verdades" e que passa ao largo de reflexões verdadeiramente sérias e honestas. ${ }^{8}$

\section{Cineastas Africanos}

Pensar numa perspectiva que coloca em relevo um número razoável de cineastas africanos, certamente causa estranheza se levarmos em consideração uma historiografia que privilegia análises fílmicas com base eurocêntrica e/ou anglófonas como objeto primordial da história, esse se traduz nas extensas bibliografias onde os referenciais teóricos normalmente são apoiados em pesquisadores/as de formação eurocêntrica e/ou norte-americana. Priorizar um olhar decolonial através do "cinema africano" é no mínimo instigante, quando se pretende uma lógica não colonizada, portanto, bem longe de ser acusada de essencializada.

Carolin Overhoff Ferreira ilustra muito bem quando afirma:

O que une os países africanos - e, assim, a grande maioria dos diretores provenientes do continente - são as marcas deixadas pela experiência do colonialismo e do neocolonialismo. No que diz respeito à arte e às indústrias

\footnotetext{
8 Podemos citar como exemplo os filmes hollywoodianos carregados de estereótipos eurocentrados: O Congo (1995), O Espírito da Selva (2007), Madagascar I (2005) e A Massai Branca (2007), filmes estes analisados na obra de Edite Nascimento Lopes: História, Cinema e Representações: a África a partir de filmes Hollywoodianos (2017).
} 
Revista do Corpo Discente do Programa de Pós-Graduação em História da UnB

Em TEMPO dE HISTÓRIAS | Brasília-DF | n. 37 | p. 28-44 | jul./dez. 2020.

ISSN 2316-1191

cinematográficas, o colonialismo tornou difícil ou até mesmo impossível o desenvolvimento independente da produção, distribuição e exibição de filmes, que ficavam sob o controle absoluto dos colonizadores. Ao fim da era colonial, ficou claro que não bastaria descolonizar os meios de criação e divulgação cinematográficos para que se atingisse um verdadeiro grau de independência. Seria fundamental, sobretudo, que houvesse um processo de descolonização das mentes, como ressalta Ngugi Wa Thiong'o. A descolonização do imaginário continua sendo tarefa indispensável para a produção cinematográfica na África, produção essa que, apesar dos obstáculos, já conta com uma longa tradição de mais de cem anos. (2014, p. 9,10)

Vale salientar que a categoria "cinema africano" é uma generalização que pode sugerir uma homogeneidade de soluções estéticas criadas por diretores de várias nacionalidades. Aqui não tomamos a totalidade da produção cinematográfica africana, mas as obras dos cineastas que concebiam o cinema como um espaço de reflexões sobre as experiências da colonização e das negociações culturais cotidianas que realizavam em casa e no exílio, lembrando se tratar de artistas pensadores que se constituíram como tradutores culturais através da politização de suas obras, engajados nas lutas socioculturais de determinados contextos históricos (TELES, 2016, p. 2), portanto, não há a pretensão de nos oferecer uma visão totalizante.

Ao pesquisar os primórdios dos filmes de ficção africanos, percebemos que suas realizações foram feitas por estrangeiros, bem como as produções na África do Sul entre 1916 e 1925, realizadas por empresas anglo-americanas. No Egito foram produzidos principalmente por cineastas exilados que moravam no Cairo ou na Alexandria. Na Argélia, Marrocos e Nigéria, após a independência foram produções realizadas por diretores europeus e norte-americanos, e posteriormente essas funções foram substituídas por africanos, sendo que o Egito a partir de estúdios próprios em meados de 1930, abriram caminhos para ter seu próprio financiamento local (ARMES, 2014, p. 21). Roy Armes destaca ainda que:

[...] O aparecimento de uma produção cinematográfica própria ocorreu em muitos outros países como consequência da independência política: Argélia, Gana, Guiné, Costa do Marfim, Marrocos, Senegal, Somália, Sudão e Tunísia nos anos 1960; Angola, Benim, Burquina Fasso, República dos Camarões, Congo, República Democrática do Congo (ex-Zaire), Etiópia, Gabão, Líbia, Madagáscar, Mali Mauritânia, Ilhas Maurício, Moçambique, Níger, Nigéria e Zimbábue nos anos de 1970. Outros países, como Guiné-Bissau e Quênia, iniciavam suas produções nos anos de 1980, Burundi, Cabo Verde, República do Chade, Tanzânia e Togo apenas nos anos de 1990; e, mais recentemente, a República Centro-Africana em 2003 (2014, p. 21e 22).

Não é difícil imaginar que no período colonial/pós-colonial/neocolonial, os colonialistas tinham dúvidas em relação à capacidade dos africanos na realização de qualquer tipo de filme, inclusive ficção, mesmo que seus cineastas expoentes tenham sido formados em escolas europeias, cuja peculiaridade de suas produções carregava características do exílio e da diáspora; e aqueles que residiam no continente africano; ficando assim, flagrante as dificuldades em conseguirem recursos para suas produções contemporâneas, inclusive para a produção de películas com forte definição identitária em seus filmes. 
Revista do Corpo Discente do Programa de Pós-Graduação em História da UnB

EM TEMPO DE HISTÓRIAS | Brasília-DF | n. 37 | p. 28-44 | jul./dez. 2020.

ISSN 2316-1191

Para melhor contextualização vale lembrar que nos primeiros anos da década de 1970, em torno de 33 cineastas originários de países subsaarianos, se uniram para reivindicar a causa do cinema perante seus respectivos governos; como resultado desta decisão política, a Féderation Panafricaine des Cinéastes (Federação Pan-africana de Cineastas) - FEPACI, desenvolveu nos anos seguintes, um tratado sobre a identidade do cinema africano, que tinha como ponto focal em sua primeira fase, a ideia de que no futuro houvesse um cinema responsável, livre e engajado, ${ }^{9}$ conforme se verifica no trecho abaixo:

\begin{abstract}
A presença do cinema no continente africano remonta, por sua vez, ao final do século XIX. O jornalista cinematográfico e crítico Emmanuel Sama indica que a primeira apresentação de L'Arroseur Arrosé, dos irmãos Lumière, ocorreu na Argélia, em 1895(!); e o mesmo filme teria sido exibido no palácio Royal em Fez, Marrocos, dois anos mais tarde. Pierre Pommier é mais cauteloso e sugere que a primeira exibição ocorreu em 1905 (ROSENSTEIN, 2014, p. 80).
\end{abstract}

As dificuldades que permeiam a consolidação de um cinema que tem como um dos objetivos privilegiar suas histórias e subjetividades, nos leva a reflexão de que não há um fazer cinematográfico homogêneo, pois sempre é possível uma pluralidade instigante que nos encaminha para uma percepção menos simplista, mas rica na construção de imaginários múltiplos, neste caso, a historiadora Ângela Teles nos apresenta um contexto interessante ao afirmar que:

O primeiro filme africano a ter reconhecimento internacional foi $A$ Negra de... (A Jovem Negra, 1966)), de Ousmane Sembène. Além deste filme, foram selecionados do mesmo diretor Camp De Thiaroye (1988), Ceddo (1977) e Moolaadé (2004) aos quais tivemos acesso. Do Senégal, também selecionamos filmes do diretor Djibril Diop Mambéty, Badou Boy (1970), Le Franc (1994), La Petite Vendeuse de Soleil (1999) e Touki Bouki (1973). Do diretor malinês Souleymane Cissé selecionamos Den Muso (1975), Finyè (1983), Baara (1978) e Yeelen (1987). Do Burkina Fasso foram selecionados os filmes de Idrissa Ouedraogo Kini and Adams (1997), Yaaba (1989), Yan Daabo (1986) e Tilai (1990). A escolha desses diretores e dos filmes citados deu-se em função da importância de suas obras para o cinema africano e da acessibilidade (2016, p.3).

Sem defender essencialismos, é possível reconhecer que cineastas africanos têm um olhar privilegiado sobre o seu continente, já que estão inseridos diretamente na complexidade do mesmo, tendo condições privilegiadas em desmistificar o caráter homogêneo que normalmente é atribuído à "África" dentro de uma análise ocidentalizada.

\title{
Hotel Ruanda (2004): representações e historicizações
}

Analisando as condições de produção do filme em questão, sendo uma película hollywoodiana com larga distribuição, temos a preocupação de refletir se Hotel Ruanda (2004) realmente ajudou ou não na proliferação de representações estereotipadas, numa perspectivas de representação de um continente aparentemente homogêneo, sem especificidades ou subjetividades dentro de um olhar ocidental/eurocêntrico. Importante destacar que o filme é uma co-produção norte-americana, sul-africana e britânica, com

${ }^{9}$ Ver: ROSENSTEIN (2014). 
Revista do Corpo Discente do Programa de Pós-Graduação em História da UnB

Em TEMPO DE HIsTóRIAS | Brasília-DF | n. 37 | p. 28-44 | jul./dez. 2020.

ISSN 2316-1191

adaptação de roteiro escrito por George Pearson e Keir Pearson; dirigida por Terry George e lançado em 2005. Foi estrelado por Don Cheadle, Ha Keem Kae-Hazim, Joaquin Phoenix, Nick Nolte e Sophie Okonedo, cujo objetivo foi de contar a história "real" de Paul Rusesabagina, numa brava tentativa de salvar a vida de sua família e diversos refugiados/as durante o genocídio de 1994 na capital Kigali em Ruanda; lhes concedendo abrigo no Hotel des Mille Collines, onde era gerente.

Esta película foi aclamada pelo público como um dos filmes mais tocantes do ano de lançamento, recebendo o Prêmio do Público no Festival Internacional de Cinema de Toronto no Canadá em 2004, com ampla divulgação, conquistando outros prêmios como: Satellite Award de Melhor Filme Dramático - 2005 - United Artists; Prêmio do Sindicato de Produtores da América - Prêmio Stanley Kramer - 2005; Prêmio do Cinema Europeu de melhor compositor, concedido pela Academia de Cinema Europeu- 2005; Satellite Award de Melhor Ator em Filme de Drama - Don Cheadle - 2005; e diversas outras indicações.

Hotel Ruanda (2004) em suas cenas iniciais, numa tela escura, sem imagens, ouvimos um áudio de uma estação de rádio mal sintonizada, com vozes sobrepostas, quando uma voz feminina fora de Ruanda anuncia: "O último cessar-fogo chegou tarde para salvar estes povoados". Continua "Hoje Clinton expressou sua preocupação com a péssima situação de Sarajevo". Logo em seguida entra uma voz masculina ruandense que diz:

\begin{abstract}
Se alguém me pergunta caros ouvintes, porque odeio os tutsis eu digo: Leia nossa história. "Os tutsis se aliaram aos colonos belgas". "Roubaram nossas terras hutus e nos açoitaram". "Agora, esses rebeldes tutsis voltaram". "São baratas". "São assassinos, Ruanda é terra dos hutus". "Somos a maioria". "Eles são uma minoria de traidores e invasores". "Acabaremos com os rebeldes da Frente Patriótica de Ruanda". "Esta é a RTLM, ${ }^{10}$ a rádio do poder hutu". "Fique alerta". "Vigie seus vizinhos".
\end{abstract}

Em outra sequência somos apresentados a Paul Rusesabagina, um homem negro ao mesmo tempo simples e refinado, de etnia hutu, e ao Hotel Mille Collines, o qual ele gerencia, na cidade de Kigali, capital de Ruanda, no ano de 1994. Apresentando sinais evidentes de levantes causados pela etnia hutu, num clima de franca perseguição a etnia tutsi. Numa das cenas, conhecemos o Coronel Oliver, enviado pela ONU11 e o General Bizimungu, onde discutem o pretendido acordo de paz da ONU, o qual o Coronel Oliver diz que não achava que os Interahamwe ${ }^{12}$, a mais importante das milícias armadas pelos hutus, iriam respeitar.

Em outra cena, vemos um jornalista branco e não africano, perguntando a um dos conhecidos de Paul, qual a diferença entre tutsis e hutus, onde esse personagem lhe explica que segundo os colonos belgas, os tutsis são mais altos e elegantes, por terem narizes mais finos e pele mais clara, condições suficientes para governarem o país. Quando os belgas foram embora, sob pressão das Nações Unidas no intuito de favorecer a independência de Ruanda, os mesmos belgas decidiram através de uma série de

\footnotetext{
10 Rádio Television Libere dês Milles Collines.

11 Organização das Nações Unidas

12 Era a mais importante das milícias armadas pelos hutus em Ruanda (Wikipédia).
} 
Revista do Corpo Discente do Programa de Pós-Graduação em História da UnB

EM TEMPO DE HISTÓRIAS | Brasília-DF | n. 37 | p. 28-44 | jul./dez. 2020.

ISSN 2316-1191

processos, com reformas e golpes, deixar o poder político para os hutus, causando assim, grandes rivalidades entre as etnias. Depois do poder estabelecido, os hutus resolveram se vingar da minoria tutsi, por tantos anos de subjugação.

No Hotel des Mille Colllines, acontece o evento que ressalta o acordo de paz que será assinado pelo presidente Juvenal Habyarimana e a FPR, 13 com um discurso do Coronel Oliver, nesta cena representando a UNAMIR, ${ }^{14}$ cuja fala demonstra acreditar no êxito do acordo de paz eminente. Por sua vez, a UNAMIR refletia um mandato extremamente restrito, dentro do capítulo VI da Carta da ONU, com o uso de armas autorizado apenas para a autodefesa, mas que ainda, assim fazia sentido face à expectativa de que "seria uma operação fácil" (ALVES, 2005, p. 103).

Posteriormente, ao voltar para casa, Paul se depara com casas sendo queimadas, e acaba por encontrar sua família e vizinhos escondidos em sua residência, por se sentirem acuados em relação aos soldados hutus e estar diante de um hutu em quem confiam.

Na sequência há a confirmação de que o presidente Habiarymana, da etnia hutu, tinha sido assassinado. Mas ainda neste momento, Paul acredita piamente que se trata de rumores causados por agitadores. Mais tarde, porém, eles ouvem a RTLM comunicar que quem matou o presidente foram os tutsis, numa franca traição, pois em vez de assinar o acordo de paz, derrubaram seu avião, dando razões suficientes para perseguirem os tutsis, sinalizando para um começo da rebelião: "cortem as árvores altas", ${ }^{15}$ conforme o irmão de Tatiana, esposa de Paul havia alertado horas antes.

A casa de Paul é revistada, e ele não tem escolha senão levar sua família e vizinhos para o Hotel Mille Collines, no caminho, eles vêem fogo, armas e pessoas sendo levadas por toda parte. A cidade foi tomada e o caos está instalado. Chegando ao hotel, vemos uma situação também caótica, pois há uma confusão entre turistas tentando achar seus passaportes, temendo por sua segurança, até então, Paul sempre aparentando tranquilidade e aconselhando-os a contatar a embaixada. Uma mensagem dos Estados Unidos é escutada na rádio, na qual é falado que eles estão fazendo todo o possível para garantir a segurança de seus cidadãos que se encontram no meio do tumulto.

Os jornalistas que estão hospedados no hotel conseguem incríveis imagens do massacre, ficando visivelmente chocados com tamanha violência e atrocidade. Eles planejam colocar no noticiário da noite, para que o mundo fique ciente do que está acontecendo. Paul afirma que exibir as imagens é a única maneira de ter uma chance de o mundo intervir e um dos jornalistas é enfático ao dizer que: "creio que as pessoas que virem essa gravação dirão: oh meu Deus! E continuarão a jantar".

\footnotetext{
13 Frente Patriótica Ruandesa

14 United Nations Assistance Mission for Rwanda, missão que foi instituída em resposta à demanda das partes contratantes da Declaração de Arusha por uma Força Neutra Internacional (FNI) que tivesse um papel ativo na implementação e monitoramento de acordos. Os proponentes de Arusha esperavam que a FNI garantisse a segurança geral no país, provesse segurança para os civis, detectasse fluxos de armas e neutralizasse grupos armados (Barnett, op. cit., p.62).

15 Sinal dado pelos hutus para cortarem os pés dos tutsis a golpes de facões.
} 
Revista do Corpo Discente do Programa de Pós-Graduação em História da UnB

EM TEMPO DE HISTÓRIAS | Brasília-DF | n. 37 | p. 28-44 | jul./dez. 2020.

ISSN 2316-1191

Quando finalmente os soldados chegam, dando esperanças a todos/as, vemos que as vidas de Ruanda, não são relevantes, pois só os turistas serão resgatados. A fala do Coronel Oliver a Paul resume bem quando diz: "Vocês são um lixo. Achamos que vocês são um lixo. O Ocidente, ${ }^{16}$ as superpotências, tudo que você acredita acham que vocês são um lixo, que não valem nada".

Vemos cenas impactantes quando todos os ocidentais vão embora, e ao mesmo tempo, uma leva de desabrigados são acolhidos no hotel, inclusive crianças órfãs, pois a ideia é não dar chance de sobrevivência as próximas gerações de tutsis. O hotel é invadido pelo exército hutu. Paul resiste sendo perspicaz, entrando em contato com Sabena - empresa a qual o hotel pertence, e os informa que os rebeldes invadiram o hotel e estão prestes a serem todos mortos. Paul diz que a única maneira de parar é contatando os franceses, pois são eles que abastecem os rebeldes hutus. Nesse momento o presidente da empresa - Tillens, consegue falar com o presidente da França e fazer com que o exército deixe o hotel em paz, causando revolta aos líderes do exército. $\mathrm{O}$ presidente Tillens comunica a Paul que também pediu que os franceses e os belgas voltassem e resgatassem quem estava no hotel, mas ele afirma categoricamente que isso não irá acontecer, por serem covardes e acharem que Ruanda não vale um só voto para nenhum deles, ou seja, ficarão pela própria sorte.

Durante a película percebemos as transformações de Paul, conforme avançam os acontecimentos, deixando de proteger apenas sua família, mas se lançando numa causa maior em salvar vidas, num genocídio gritante, fica flagrante essa transformação quando Paul, num momento de situação desesperadora, ao voltar para o Hotel depois de ir buscar suprimentos, se depara com centenas de corpos de cadáveres estirados na estrada que circula o rio, aliás, percurso orientado como mais seguro pelo líder rebelde George Rutaganda, numa franca demonstração de poder, mostrando a Paul a verdadeira realidade que o circunda.

Quando o genocídio atinge a marca de 500 mil mortos aproximadamente, o Coronel Oliver volta com boas notícias, de que conseguiram vistos de saída para algumas das famílias refugiadas, resultado do esforço de ruandeses que ligaram para todos os contatos possíveis fora de Ruanda, pedindo ajuda e os responsabilizando pela morte eminente, conforme orientação de Paul aos refugiados no hotel. A família de Paul é uma das selecionadas para ir à Bélgica, mas ele toma a difícil decisão de ficar e continuar ajudando aqueles que não puderam ir embora com suas famílias, liberando sua família a seguir viagem.

Nesse momento dramático, as famílias que saiam do hotel num comboio, escoltada pelas minguadas forças da ONU, foram denunciadas aos rebeldes por um funcionário hutu, desde o início hostil em relação às decisões humanitárias de Paul, sendo os caminhões que transportavam os refugiados, invadidos numa nítida emboscada. Porém, com a ajuda de Paul, que entra em contato com o coronel ruandense,

\footnotetext{
16 Quando nos referimos ao Ocidente, queremos dizer que é tudo que esteja inserido numa cultura social/econômica eurocêntrica e anglófona. Uma referência política contemporânea para essa discussão é Edward S. Said na obra: Orientalismo: O Oriente como invenção do Ocidente.
} 
Revista do Corpo Discente do Programa de Pós-Graduação em História da UnB

Em TEMPO dE HISTÓRIAS | Brasília-DF | n. 37 | p. 28-44 | jul./dez. 2020.

ISSN 2316-1191

que o ajuda através de subornos, conseguem fugir e voltar ao hotel, já numa situação limite, sem proteção nenhuma, totalmente numa condição de vulnerabilidade.

Próximo ao desfecho, vemos um flagrante ato de resistência, quando rebeldes tutsis tomam metade da cidade e propõe um acordo aos generais hutus, que neste instante estão dispostos a aceitar, negociando a libertação de seus prisioneiros hutus em troca de libertarem os seus prisioneiros tutsis. Depois de algumas tensões, os soldados da ONU, junto com rebeldes tutsis, chegam e levam todos os abrigados no hotel para um lugar seguro, onde posteriormente seriam encaminhados para Tanzânia, antes percorrendo caminhos de flagrantes destruições.

Inegavelmente trata-se de um filme sensível às sociabilidades e condições históricas que permeavam Ruanda, tocando em temas caros no que se refere ao genocídio de Ruanda em 1994; e o papel histórico da intervenção colonizadora no país. Fomentando rivalidades através da mídia, bem como o descaso internacional em relação a um conflito gritante de proporções inimagináveis; relações sociais que vão muito além das questões políticas impostas, como os casamentos e vínculos interétnicos; e falta de importância que o "Ocidente" deu a um país do continente africano, localizado na África centro-oriental, na região dos Grandes Lagos, fazendo limites com a República Democrática do Congo, Tanzânia, Uganda e Burundi.

Interessante ressaltar que o protagonista dessa película, Paul Rusesabagina, foi consultor para que esse filme fosse realizado, portanto, trata-se do olhar de quem vivenciou tais atrocidades, resultando na morte de aproximadamente um milhão de pessoas, nesse sentido, Ana Cristina Araújo Alves afirma:

O genocídio ruandês de 1994, além de ofender profundamente a consciência de humanidade pelo caráter, dimensão e velocidade das atrocidades cometidas, também engendrou uma crise humanitária regional de escala sem precedentes. As consequências do genocídio não se limitaram ao quase um milhão de vítimas diretas. Juntamente com a luta entre FPR e as FAR, a violência genocida forçou a fuga de cerca de 250.000 ruandeses para a Tanzânia e de quase 2 milhões de ruandeses para campos de refugiados no Zaire e na zona francesa protegida pela Operação Turquesa (Jones, 1995, p. 244 e Id. 2001, p. 136-137). Durante todo o mês de abril, a maioria da atenção internacional estava direcionada para as eleições da África do Sul e para a Bósnia. Quando a mídia se voltava para Ruanda, ele tinha de ficar à distância porque a situação de (in)segurança não permitia qualquer reportagem direta. O resultado foi que o genocídio foi um evento "privado", ocorrendo dentro de "portas fechadas" (Barnett, op. cit., p. 149). A crise de refugiados mobilizou a primeira cobertura visual contínua dos horrores de Ruanda, que por sua vez motivou uma explosão de simpatia e assistência. Esses eventos provocaram a mais extensiva de todas as intervenções em Ruanda: o influxo de agências de assistência humanitária da ONU e de Organizações Não Governamentais (ONGs) a Ruanda e cercanias (2005, p. 125).

Não podemos desconsiderar o processo histórico que levou ao genocídio de Ruanda no final do século XX, que implica todo o processo de colonização e suas flagrantes consequências; não devendo se restringir numa análise imediatista e simplista, levando ao equívoco de pensar que todo o conflito ocorrido em Ruanda, foi proveniente de uma crise étnica levada a grandes proporções. Isentando assim, a grande responsabilidade das grandes potências do Ocidente. Por outro lado, desconsiderando as flagrantes resistências internas que convergiram em atitudes como as de Paul Rusesabagina. 
Revista do Corpo Discente do Programa de Pós-Graduação em História da UnB

Em TEMPO dE HISTÓRIAS | Brasília-DF | n. 37 | p. 28-44 | jul./dez. 2020.

ISSN 2316-1191

\section{O Último Rei da Escócia (2006): representações e historicizações}

Já o filme "O Último Rei da Escócia", lançado no ano de 2007 no Brasil, recebeu diversos prêmios ${ }^{17}$, sendo dirigido por Kevin Macdonald ${ }^{18}$, com elenco composto por: Forest Whitaker19, James MaAvoy, Kerry Washington, Gillian Anderson, Simon Mcburney, David Oyelowo, Adam Kotz e Stephen Rwangezi. Primeiramente vale destacar que Idi Amin Dada, foi um ditador em Uganda durante os anos de 1971 a 1979, portanto, uma personalidade emblemática para contextualizar esse momento crítico da história de Uganda. O que vemos na adaptação do livro homônimo de Giles Foden para o cinema, foi o protagonismo de um médico branco escocês, Nicholas Garrigan, verdadeiro responsável por nos apresentar essa história que mistura ficção com realidade, através de um olhar estrangeiro, não africano. ${ }^{20}$

Percebemos tal trajetória logo nas cenas iniciais do filme, quando da formatura em sua terra natal a Escócia, onde Nicholas Garrigan demonstra ter uma relação protocolar e aparentemente fria com seus pais, e o desejo de trilhar seus próprios passos, decidindo aleatoriamente ir para um país de um continente que mal conhecia, e muito menos ao país de destino - Uganda. Sua motivação era de iniciar efetivamente sua carreira médica e ao mesmo tempo uma aventura.

No trajeto para o local que lhe esperam, na cidade de Mogambo, nos é descortinado uma vida de extrema pobreza no meio rural, condições precárias nas instalações do hospital local, ao qual irá trabalhar, reforçando um imaginário depreciativo do continente, com concepções do senso comum no que se refere a essa parte do mundo.

A película destaca os envolvimentos amorosos do protagonista, próprio de uma juventude a ser vivenciada em sua plenitude, inclusive o envolvimento amoroso com uma das esposas de Idi Amin Dada no decorrer do filme - Kay Amin, que acaba sendo assassinada pelo ditador, após uma tentativa de aborto. Nicholas Garrigan se mostra totalmente alheio aos problemas políticos em que o país estava enfrentando, demonstrando total desconhecimento da real figura de Idi Amin Dada e o que ele representava no que se referem suas relações culturais, políticas e socioeconômicas em Uganda.

A construção do personagem do ditador nos é apresentado como um misto de sádico, megalômano, tirânico infantilizado; basicamente, características que o Ocidente

17 British Independent Film Award - Melhor Realização Técnica, Anthony Dod Mantle (2006); Prêmio BAFTA de Cinema: Melhor Filme Britânico (2007); Prêmio BAFTA de Cinema: Melhor Roteiro Adaptado

- Peter Morgan e Jeremy Brock (2007);

${ }^{18}$ Britsh Independent Film Award: Melhor Diretor - Kevin Macdonald (2006)

${ }_{19}$ Ator consagrado com diversos prêmios como: Sattelite Award de Melhor Ator em Filme de Drama Forrest Whitaker (2006); London Film Critics Circle Awards for Best Actor, Forest Whitaker (2006); New York Film Critics Circle Award de Melhor Ator, Forest Whitaker (2006); National Board of Riview de Melhor Atore, Forest Whitaker (2006); Los Angeles Film Critics Association Award de Melhor Ator Forest Whitaker (2006); Prêmio da Sociedade Nacional de Críticos de Cinema para Melhor Ator - Forest Whitaker (2007); Bet Award: Melhor Ator - Forest Whitaker (2007); Oscar de Melhor Ator - Forest Whitaker (2007); Prêmio Globo de Ouro: Melhor Ator em Filme Dramático - Forest Whitaker (2007); etc. ${ }^{20}$ Kevin Macdonald é também documentarista, se propondo em trabalhar com obras de ficção baseadas em fatos reais. 
Revista do Corpo Discente do Programa de Pós-Graduação em História da UnB

EM TEMPO DE HISTÓRIAS | Brasília-DF | n. 37 | p. 28-44 | jul./dez. 2020.

ISSN 2316-1191

lhe imputou através da história, por conta dos atos de extermínio aos seus inimigos e desafetos, inclusive pessoas de suas relações mais próximas, como nos lembra Guilherme Felke Senger:

\begin{abstract}
A escolha de retratar a história de Amin age de forma a contribuir para a confusão entre o que são fato e o que foi criado. Os realizadores do filme reconhecem Amin como uma figura controversa e assim explicitam como coloca o diretor Kevin Macdonald: "Não dá para apontar exatamente o que é a realidade histórica e a ficção no filme". No sentido de ambientar um "tom histórico" no "Último Rei da Escócia", ressalta-se que a escolha do diretor Macdonald não aparece como isenta, pois ele nunca dirigira um filme de ficção antes e sendo, até então, um renomado documentarista, a opção por ele parece à opção por um discurso mais preocupado historicamente (2012, p. 536).
\end{abstract}

Numa perspectiva decolonial nos causa um grande incômodo vermos retratado um país em franca destruição, com condições muito precárias, falta de saneamento básico, sistema de saúde em colapso, exceto na capital Kampala, nas mãos de um ditador descontrolado, irascível. As personagens brancas, como o próprio Nicholas Garrigan, os ingleses do Alto Comissariado do Ministério das Relações Exteriores, a enfermeira branca, personagem de Gillian Anderson; representam o lado mais sóbrio em meio ao caos, com exceção do médico negro, interpretado por David Oyelowo, que demonstra profundos conhecimentos da sociedade que habita e uma sobriedade admirável. Tais representações se mostram recorrentes nas produções hollywoodianas no que se refere ao continente, como se o Ocidente e seus representantes fossem a verdadeira tábua de salvação, e os africanos seres infantilizados, incapazes de viverem sem a tutela ocidental.

Um dado muito interessante é que mesmo tendo elementos flagrantes de que parte da história de Uganda foi contada pela perspectiva de um olhar europeu, o filme em questão possui uma ampla participação africana quando analisamos a equipe envolvida em sua produção. Sendo rodado em Uganda, contando com a participação de ugandenses em papéis de pouco destaque e figurativos, mas mesmo assim, importante para a economia local (SENGER, 2012), inclusive na recriação dos momentos históricos relatados, com as contribuições de atores contemporâneos a Idi Amin Dada, que relataram os horrores da época, inclusive com a morte de parentes próximos.

Já nos momentos finais da trama, quando o médico pessoal do ditador Idi Amin Dada, é surrado e torturado, e diante de sua morte eminente, num descuido da guarda pessoal do ditador, o mesmo é salvo pelo médico negro Dr. Junju, personagem de David Oyelowo, dando assim oportunidade para que Nicholas Garrigan fugisse e contasse ao mundo o que estava acontecendo em Uganda, mostrando a verdadeira face do ditador, o que é demonstrado nesse diálogo:

Porque está fazendo isso? (Dr. Nicholas); "Sinceramente, eu não sei", "Você merece morrer, mas morto você não pode fazer nada", "Vivo ainda terá a chance de se redimir" (Dr. Junju); "Eu não entendo" (Dr. Nicholas); "Estou cansado de ódio, Dr. Garrigan", "Este país está se afogando nele.", "Nós merecemos mais do que isso.", "Vá para casa. Conte ao mundo a verdade sobre Amin.", "Eles acreditarão em você.", "Você é um homem branco" (Dr. Junju).

No trecho transcrito acima, vemos a tensão entre os personagens, um médico branco escocês e um médico negro ruandês, o primeiro carrega os privilégios de uma 
Revista do Corpo Discente do Programa de Pós-Graduação em História da UnB

EM TEMPO DE HISTÓRIAS | Brasília-DF | n. 37 | p. 28-44 | jul./dez. 2020.

ISSN 2316-1191

hierarquização imposta, já o outro consciente de sua real importância social e racial. Nesse caso cabe para reflexão a afirmação de Joseph Ki-Zerbo:

Outra exigência imperativa é de que a história (e a cultura) da África deve pelo menos ser vistas de dentro, não sendo medidas por réguas de valores estranhos... Mas essas conexões têm que ser analisadas nos termos de trocas mútuas, e influências multilaterais em que algo seja ouvido da contribuição africana para o desenvolvimento da espécie humana. (2010, vol I, p.VII)

O homem branco europeu/ocidentalizado é aquele que possui licença da palavra, da "verdade", narrando uma parte da história de Idi Amin Dada em "O Último Rei da Escócia (2006)" de maneira oficial, presumindo assim, credibilidade e reafirmando uma hierarquia social em que africanos se encontram na base desta mesma hierarquia, desautorizados a narrar sua própria narrativa, basta olharmos para o personagem principal representado por Forest Whitaker, negando seu protagonismo, mesmo que fora de controle, assim confirmando para o mundo que a África é o grande e histórico celeiro da Europa.

\section{Considerações Finais}

[...] A atitude histórica africana não será então uma atitude vingativa nem de auto-satisfação, mas um exercício vital da memória coletiva que varre o campo do passado para reconhecer suas próprias raízes. Após tantas visões exteriores que têm modelado a marca registrada da África a partir de interesses externos (até nos filmes contemporâneos), é tempo de resgatar a visão interior de identidade, de autenticidade, de conscientização: "volta repatriadora", como diz Jacques Berque para designar esse retorno às raízes. Ao considerar o valor da palavra e do nome na África, ao pensar que atribuir nome a uma pessoa é quase apoderar-se dela - a tal ponto que os personagens venerados (pai, esposo, soberano) são designados por perífrases e cognomes -, compreenderemos por que toda série de vocábulos ou conceitos, todo o arsenal de estereótipos e de esquemas mentais relativos à história da África situam-se no contexto da mais sutil alienação. É preciso aqui uma verdadeira revolução copernicana, que seja primeiramente semântica e que, sem negar as exigências da ciência universal, recupere toda a corrente histórica desse continente, em novos moldes. (KIZERBO, 2010, p. LIII)

A pretensão em delinear um fio condutor dessas narrativas, se é que existem, destacando como essas obras cinematográficas contribuiriam para conhecer melhor o continente africano em suas diversas perspectivas, e/ou na construção de "verdades", imaginários, quando se refere ao continente não é um trabalho fácil. Se há ou não a reprodução de estereótipos, que invisibilizam ou silenciam as diversas vozes do continente africano, não se mostraram explícitas em Hotel Ruanda (2004); pois as abordagens na obra procuraram respeitar os acontecimentos e deram voz a uma população invisibilizada/silenciada, através do personagem Paul Rusesabagina. Já em O Último Rei da Escócia (2006), o incômodo foi perceber que a memória estava nas mãos do médico branco/escocês Nicholas Garrigan, perspectiva essa no mínimo controversa dentro de um olhar decolonial, onde a perspectiva eurocêntrica é questionada.

Uma vez que há poucos trabalhos na historiografia voltados a esse recorte de análise cinematográfica, priorizando a perspectiva e uma epistemologia que valorize o 
Revista do Corpo Discente do Programa de Pós-Graduação em História da UnB

Em TEMPO DE HIsTóRIAS | Brasília-DF | n. 37 | p. 28-44 | jul./dez. 2020.

ISSN 2316-1191

recorte étnico-racial e decolonial. Pretende-se fugir do lugar comum, neste caso, as construções mentais eurocêntradas. Faz-se necessário compreender como essas relações contribuíram para construção de certos imaginários na sociedade brasileira e no mundo, levando em conta o uso do Cinema como instrumento didático para uma melhor compreensão do continente africano, e transportando para nossa sociedade contemporânea, onde as imagens são fortes fixadores de realidades.

Tanto o filme Hotel Ruanda (2004), quanto O Último Rei da Escócia (2006), apresenta-nos enredos impactantes, com imagens fortes e uma qualidade indiscutível dentro do padrão estético hollywoodiano, ferramentas sedutoras para uma contextualização histórica, porém o primeiro filme talvez por se tratar de um momento histórico baseado em fatos reais, cuja consultoria para sua realização foi feita pelo personagem principal da película, Paul Rusesabagina. Carrega uma "verdade" licenciada, respeitando a veracidade dos fatos acontecidos no genocídio de Ruanda, denunciando o descaso das "grandes potências" e seu flagrante esquecimento em relação a uma população de "segunda categoria" como são tratadas as diversas populações do continente africano.

Já O Último Rei da Escócia (2006), respeitando a beleza estética da obra e a indiscutível interpretação dos atores, neste caso, destacando o ator Forest Whitaker, nos causa incômodos, pois há representações carregadas de clichês e estereótipos voltados ao continente. Mesmo tendo a consciência de que a opção foi de construir um filme de ficção com pitadas de realidade. É constrangedor quando seu olhar predominante passa pelo crivo de um homem branco europeu, fato este que precisa mais uma vez ser destacado; alertando-nos quanto aos silenciamentos e invisibilidades persistentes nas construções de cineastas que se propõe a representar uma história já condicionada, no prisma de um olhar estrangeiro. Não há como negar a figura controversa do ditador Idi Amin Dada em Uganda, e suas atrocidades documentadas; mas as imagens construídas fixam em momentos de destruição, pobreza, doenças, insanidades, prostituição, misticismo religioso; construções essas vinculadas ao atraso de uma nação.

Ao abordar essas obras cinematográficas como possibilidades de discutir marcos históricos ocorridos em dois países que fazem parte do continente africano, Ruanda e Uganda, se mostra extremamente positivo, desde que apoiados em informações que desvelem o continente como algo que possui subjetividades, respeitando as especificidades de cada país abordado. Seus recortes políticos e temporais, as influências da colonização na construção de rivalidades étnicas, em destaque Ruanda e o papel na construção política e social em Uganda, com suas implicações extremas que levaram ao golpe do ditador Idi Amin Dada e suas relações internacionais fora de África, que poderiam muito bem terem sido trabalhadas melhor, bem como o fato do ditador ter essa fixação pela Escócia, é no mínimo emblemático e desafiador para cineastas e historiadores/as abertos a verdadeiros desafios. 
Revista do Corpo Discente do Programa de Pós-Graduação em História da UnB

Em TEMPO dE HistóRIAS | Brasília-DF | n. 37 | p. 28-44 | jul./dez. 2020.

ISSN 2316-1191

\section{Referências}

ALVES, Ana Cristina Araújo. Contos Sobre Ruanda: Uma análise crítica das narrativas sobre o genocídio ruandês de 1994. Dissertação (Mestrado) - Pontifícia Universidade Católica do Rio de Janeiro, Instituto de Relações Internacionais, 2005.

ARMES, Roy. O Cinema Africano: Uma Tentativa de Definição. In. FERREIRA, Carolin Overhoff. África um continente no cinema. São Paulo: Editora Unifesp, 2014.

AUMONT, Jacques. A estética do filme. Campinas, São Paulo: Papirus, 1995.

. A imagem. Campinas, São Paulo: Papirus, 1993.

- Dicionário Teórico e Crítico de Cinema. Jacques Aumont, Michel Marie; tradução: Eloisa Araújo Ribeiro. Campinas, SP: Papirus, 2003.

BAMBA, Mahomed; MELEIRO, Alessandra (orgs), Filmes da África e da diáspora: ojetos de discursos. Salvador: EDUFBA, 2012.

BURKE, Peter. Testemunha Ocular: História e Imagem.Bauru: EDUSC, 2004.

. A escrita da história: novas perspectivas. São Paulo: Editora Unesp, 2011.

FERREIRA, Carolin Overhoff (org). África um continente no cinema. São Paulo: Editora Unifesp, 2014.

FERRO, Marc. O Cinema e História. Rio de Janeiro: Paz e Terra, 1992.

HALL, Stuart. Cultura e Representação. Tradução: Daniel Miranda e William Oliveira. Rio de Janeiro: Ed. PUC-Rio: Apicuri, 2016.

A Identidade cultural na pós-modernidade. Rio de Janeiro: DP\&A, 2002.

Da Diáspora: Identidades e mediações culturais. Belo Horizonte: UFMG, Representações da UNESCO no Brasil, 2003.

JOLY, Martine. Introdução à Análise da Imagem. Campinas: Papirus Editora, 2012.

KI-ZERBO, Joseph. Introdução Geral. In. História Geral da África I: Metodologia e préhistória da África/editado por Joseph Ki-Zerbo, e ed. rev. Brasília: UNESCO, 2010

KORNIS, Mônica Almeida. Cinema, televisão e história. Rio de Janeiro: Jorge Zahar Ed, 2008.

História e Cinema: um debate metodológico. Estudos Históricos. Rio de Janeiro, RJ. v.5, n.10, p. 237- 250.

LOPES, Edite Nascimento. História, Cinema e Representações: a África a partir de filmes Hollywoodianos. Curitiba: Editora Prismas, 2017.

NASCIMENTO, Renata Melo Barbosa do. Rio, 40 Graus: Representações das Mulheres Negras no Filme de Nelson Pereira dos Santos (1955). Dissertação (Mestrado) - UnB, História, 2014.

OLIVA, Anderson Ribeiro. Reflexos da África: ideias e representações sobre os africanos no imaginário ocidental, estudos de caso no Brasil e em Portugal. Goiânia: Ed. PUC Goiás, 2010 
Revista do Corpo Discente do Programa de Pós-Graduação em História da UnB

Em TEMPO DE HIsTóRIAS | Brasília-DF | n. 37 | p. 28-44 | jul./dez. 2020.

ISSN 2316-1191

. Olhares sobre a África: Abordagens da História Contemporânea da África nos livros didáticos brasileiros. História Revista, v.14, n.1, p.17-35. 18 nov, 2009.

OLIVEIRA, Luiz Fernandes de, CANDAU, Vera Maria Ferrão. Pedagogia Decolonial e Educação Antirracista e Intercultural no Brasil. disponível em: http://www.labtecgc.udesc.br/tabd1/bitstream/handle/123456789/24110/candau_pedago gia_antirracista_anticolonial_br.pdf?sequence=1\&isAllowed=y. acesso em 04/04/2018.

ROSENSTEIN, Johannes. Uma Breve História do Cinema Africano: Relato de Viagem. In: FERREIRA, Carolin Overhoff (org). África um continente no cinema. São Paulo: Editora Unifesp, 2014.

SAID, Edward W. Orientalismo: o Oriente como invenção do Ocidente. tradução: Rosaura Eichenberg. $1^{a}$ ed.. São Paulo: Companhia das Letras, 2007.

SENGER, Guilherme Felkl. História da África Comtemporânea e Cinema: estudo das representações dos filmes "O Último Rei da Escócia", "Diamante de Sangue" e "O Jardineiro Fiel". disponível em: http://www.seer.ufrgs.br/aedos/article/view/30849. acesso em 25/03/2018.

SHOHAT, Ella; Stam, Robert. Crítica da Imagem Eurocêntrica: multiculturalismo e representação. São Paulo: Cosac Naify, 2006.

STAM, Robert. Introdução à teoria do Cinema. Tradução: Fernando Mascarello. Campinas, SP: Papirus, 2003.

TELES, Ângela Aparecida. O Cinema Africano de Osmane Sembène e Djibril Diop Mambéty. disponível

em:

http://encontro2016.mg.anpuh.org/resources/anais/44/1469241731_ARQUIVO_O

Cinema Africano de Ousmane Sembene e Dijibril Diop Mambety.pdf. acesso em 19/02/2018. 